\title{
Lipoma Arborescens de Joelhos
}

\section{Lipoma Arborescens of the Knees}

\author{
Carlos Frederico Rodrigues Parchen ${ }^{(1)}$, Eduardo dos Santos Paiva ${ }^{(2)}$
}

\begin{abstract}
RESUMO
Lipoma Arborescens é uma lesão intra-articular rara e benigna, de etiologia desconhecida, caracterizada por proliferação vilosa sinovial e substituição do tecido subsinovial por tecido gorduroso maduro. Essa condição faz parte dos diagnósticos diferenciais no caso de uma articulação lenta, progressiva e cronicamente edemaciada. Apresentamos um caso de envolvimento bilateral em joelhos e discutimos sintomas, diagnóstico e tratamento dessa doença.
\end{abstract}

Palavras-chave: Lipoma Arborescens, membrana sinovial, joelho.

\section{INTRODUÇÃO}

Lipoma Arborescens (LA, lipomatose articular difusa) é uma lesão intra-articular, rara e de etiologia desconhecida, caracterizada por proliferação das vilosidades sinoviais e substituição difusa do tecido sinovial por células gordurosas maduras. A lesão é mais freqüente em adultos e distribui-se igualmente entre os sexos. Na maioria das vezes é monoarticular, habitualmente envolvendo o joelho. Essa entidade encontra-se entre os diagnósticos diferenciais de uma articulação cronicamente edemaciada ${ }^{(1)}$.

\section{RELATO DE CASO}

Paciente do sexo masculino, 33 anos de idade, aos seis anos de idade teve dor e aumento de volume do joelho direito, com rigidez importante. Morava nos Estados Unidos, e nesta ocasião foi feito o diagnóstico de artrite reumatóide juvenil (ARJ). Segundo informação dos pais, relata que o tratamento foi feito com base em aspirações e infiltrações repetidas do joelho direito, com períodos longos com pouca sintomatologia. $\mathrm{Na}$ época, teve discreto envolvimento do tornozelo direito. Usou também paracetamol e ácido acetilsalićlico em doses variáveis.

Após oito anos de quadro oligoarticular, iniciou com artrite envolvendo joelhos esquerdo e direito, além do tornozelo esquerdo. Iniciou uso de cloroquina e antiinflama-

\begin{abstract}
Lipoma Arborescens is a rare, benign, intra-articular lesion, of unknown etiology, characterized by villous proliferation of the synovium and diffuse replacement of the subsynovial tissue by mature fat cells. It forms part of the differential diagnosis for a slowly progressive chronically swollen joint. We present a case of bilateral involvement of the knees and discuss the symptoms, diagnosis and treatment of this condition.
\end{abstract}

Keywords: Lipoma Arborescens, synovial membrane, knee.

tórios não-hormonais, com resposta adequada e discretos períodos de flare. Após 16 anos do início do quadro, teve artrite de primeira metacarpofalangeana à esquerda e punho esquerdo, e cerca de três anos depois teve envolvimento de metacarpeanos e punho à direita. Iniciou tratamento com leflunomida, prednisona, $10 \mathrm{mg}$, e meloxicam. Ao cessar, por conta própria, o uso de leflunomida, desenvolveu novo flare da doença e veio para reavaliação.

$\mathrm{Na}$ história pregressa, apresentava obesidade mórbida, tendo sido submetido à gastroplastia dois anos antes da consulta atual. Não houve intercorrências pós-operatórias, e referiu melhora das dores nos joelhos com a perda de peso. Negava psoríase, queixas oculares, sintomas sicca, lombalgia inflamatória, tendinite, queixas gastrintestinais ou urinárias. Estava em uso de meloxicam, $15 \mathrm{mg}$, alternando com lumiracoxibe, $400 \mathrm{mg}$.

Ao exame físico, apresentava dados vitais normais, com exame segmentar sem particularidades. Apresentava sinovite ativa de punho esquerdo, quinta metacarpofalangeana à direita, primeira metacarpofalangeana à esquerda, joelhos e tornozelo esquerdo.

Trazia radiografias de joelhos que mostravam erosões em platô tibial à esquerda; ressonância magnética (RM) recente trazia erosões de joelhos bilaterais, com grandes lipomas arborescentes envolvendo as cavidades articulares (Figuras 1 a 4). Pela evidência persistente da sinovite em

Recebido em 29/2/2008. Aprovado, após revisão, em 24/4/2008. Declaramos a inexistência de conflitos de interesse.

1. Médico reumatologista, voluntário do Serviço de Reumatologia do Hospital de Clínicas da Universidade Federal do Paraná (UFPR)

2. Professor-assistente da disciplina de Reumatologia do Hospital de Clínicas da UFPR.

Endereço para correspondência: Carlos Frederico Rodrigues Parchen, Rua Frei Fabiano de Cristo, 603, 81530-110, Curitiba, PR, Brasil, e-mail: carlosparchen@yahoo.com.br. 
mãos - apresentava sinovite ativa de punho esquerdo, quinta metacarpofalangeana à direita, primeira metacarpofalangeana à esquerda e de tornozelos -, considerou-se que a artrite reumatóide do paciente estava ativa. Foi, então, mantido com leflunomida, $20 \mathrm{mg}$ + lumiracoxibe, $100 \mathrm{mg}$, e foram feitas infiltrações de triancinolona hexacetonida em punho esquerdo e nas metacarpofalangeanas afetadas. Encontra-se agora estável clinicamente, com melhora da sinovite.

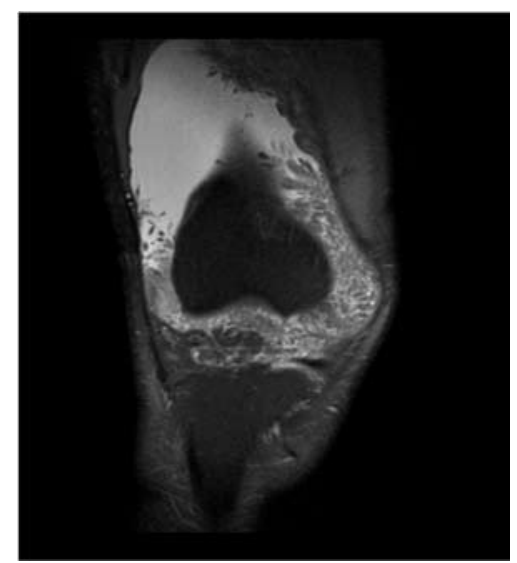

Figura 1 - Ressonância magnética coronal de joelho direito mostrando lesão arborescente.

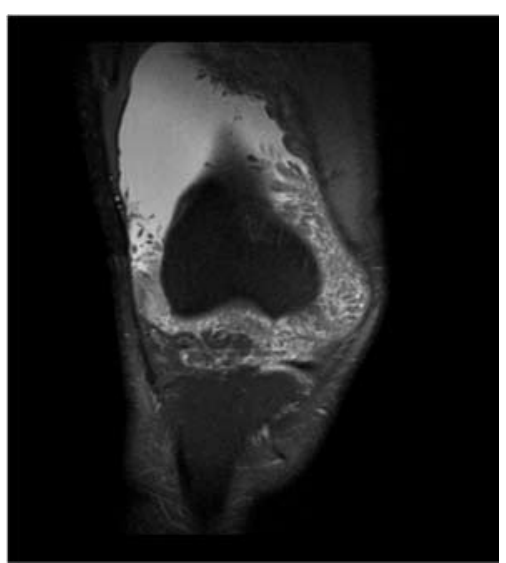

Figura 2 - Ressonância magnética coronal de joelho esquerdo mostrando lesão arborescente.

\section{DISCUSSÃO}

Lipoma Arborescens (lipomatose articular difusa) é uma lesão intra-articular, benigna, rara e de etiologia desconhecida. Caracterizada por proliferação das vilosidades sinoviais e

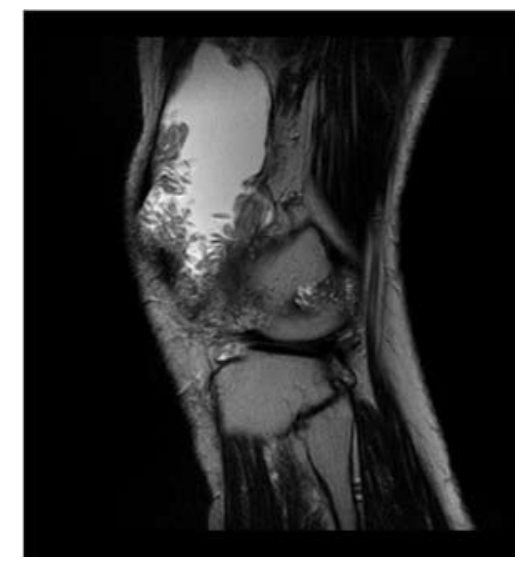

Figura 3 - Ressonância magnética sagital de joelho direito mostrando lesão arborescente.

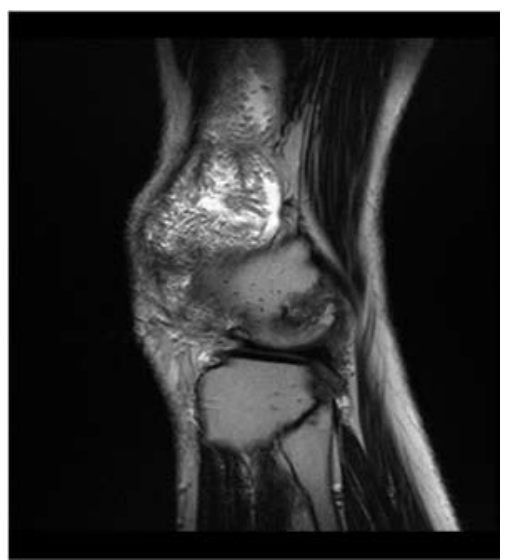

Figura 4 - Ressonância magnética sagital de joelho esquerdo mostrando lesão arborescente.

substituição difusa do tecido sinovial por células gordurosas maduras. Geralmente, a lesão é monoarticular, de crescimento lento e pouco doloroso. A maioria dos casos descritos envolve o joelho (região suprapatelar), entretanto o quadril, o ombro, o punho e o cotovelo também podem ser acometidos. Alguns casos mostram mais de uma articulação envolvida.

Os pacientes apresentam derrame progressivo e de longa data na articulação envolvida, podendo haver dor e diminuição da amplitude de movimento. Clinicamente encontra-se edema macio suprapatelar. Podem coexistir osteoartrite $(\mathrm{OA})$, história de trauma local e diabetes melito. A idade de aparecimento da lesão está na faixa entre 9 e 68 anos e distribui-se igualmente entre os $\operatorname{sexos}^{(1)}$.

O LA está entre os diagnósticos diferenciais de uma articulação cronicamente edemaciada. Outras causas incluem artrite reumatóide, sinovite vilonodular pigmenta- 
da, lipoma sinovial, artropatia amilóide e condromatose sinovial. Testes laboratoriais (VHS, fator reumatóide, ácido úrico sérico, HLA-B27) são normais. Radiografias simples podem mostrar aumento de volume das partes moles da região suprapatelar e auxiliam a descartar outras causas de dor e edema. A aparência das lesões na RM é diagnóstica: massa sinovial intra-articular com morfologia frondosa e sinal de alta intensidade. A intensidade do sinal é suprimida nas seqüências com supressão de gordura, e a falta de realce após injeção de gadolíneo exclui processos inflamatórios ou neoplásicos. Não há suscetibilidade a efeitos magnéticos em razão de hemossiderina ou calcificação( ${ }^{(1)}$. O diagnóstico de LA era freqüentemente histológico, mas atualmente a RM é suficiente para estabelecer o diagnóstico. Em 21 dos 33 casos relatados por Vilanova et al. ${ }^{(2)}$, o diagnóstico de LA foi realizado somente por intermédio de RM.

Macroscopicamente, o LA é uma massa de tecido volumoso de aparência frondosa composto por numerosos vilos de tecido gorduroso amarelo. Histologicamente, os vilos são compostos por tecido adiposo maduro (com grandes adipócitos), deslocando outros tecidos ao redor da articulação. Podem ser encontrados capilares aumentados e congestos. Além disso, encontra-se sinóvia reacional com citoplasma eosinofílico $^{(1)}$.

Kim et al. ${ }^{(3)}$, ao descreverem um caso histologicamente comprovado de LA, discutem que embora a causa de OA no LA seja desconhecida, em alguns casos parece haver uma relação entre LA e OA. Hallel et $a l^{(4)}$ sugerem que efusão e espessamento sinovial prolongados, causados provavelmente por dano mecânico repetitivo aos vilos proliferados, eventualmente levam à OA. Avaliando outros cinco casos, semelhantes ao descrito por Kim et al. ${ }^{(3)}$, postula-se uma relação causal entre LA e OA.

Sabe-se que o LA geralmente é monoarticular e preferencialmente envolve o joelho. Apesar disso, Beija et al. ${ }^{(5)}$

\section{REFERÊNCIAS}

1. Davies AP, Blewitt N: Lipoma arborescens of the knee. The Knee 12: 394-6, 2005.

2. Vilanova JC, Barcelo J, Villalon M, et al.: MR Imaging of lipoma arborescens and the associated lesions. Skeletal Radiol 32: 504-9, 2003.

3. Kim RS, Song JS, Park SW, et al.: Lipoma Arborescens of the Knee. Arthroscopy 20(8): e95-9, 2004.

4. Hallel T, Lew S, Bansal M: Villous lipomatous proliferation of the sinovial membrane (lipoma arborescens). J Bone Joint Surg Am 70: 264-70, 1998. descreveram um caso de LA multifocal localizado nos joelhos e quadris de um homem com 24 anos de idade, inicialmente sugerindo quadro de artropatia inflamatória. Os autores discutem que o caso relatado parece ser o terceiro caso de LA multifocal relatado na literatura. Outros dois casos foram descritos por Martin et al. ${ }^{(6)}$ e Siva $e t ~ a l .{ }^{(7)}$. O caso descrito por Siva et al. ${ }^{(7)}$ diz respeito a um homem de 20 anos de idade com síndrome do intestino curto congênito e LA de joelhos, punhos e mãos. Discute-se ainda, no artigo de Beija $e t ~ a l .^{(5)}$, que algumas lesões gordurosas da sinóvia são erroneamente rotuladas como LA por não encontrarem dois critérios essenciais: a lesão difusa e a característica proliferação da hiperplasia vilosa lipomatosa da sinovial. Não encontramos, na literatura especializada, outros relatos de pacientes que tivessem sido submetidos à gastroplastia e que, na evolução, apresentassem LA em alguma articulação. Além disso, no caso do paciente relatado, a revisão da literatura não nos permitiu inferir se as erosões encontradas nos joelhos deviam-se aos lipomas ou à artrite reumatóide. Pela atividade da doença em outras articulações, a impressão dos autores é de que se trata de erosões da doença reumatóide.

O tratamento é realizado com injeções intra-articulares de compostos radioativos como o Yttrium 90 ou esteróides, trazendo alívio dos sintomas por períodos curtos a moderados. O tratamento cirúrgico geralmente é recomendado, inclui excisão completa por meio de sinovectomia total, por cirurgia aberta ou artroscópica ${ }^{(1)}$. A sinovectomia artroscópica com pequenas incisões possibilita ressecar toda massa suprapatelar, mesmo bilateralmente, mostrando pouca morbidade. Nas lesões mais extensas, uma abordagem transquadricipital, associada à sinovectomia artroscópica, pode ser utilizada. Baixas taxas de recorrência são esperadas, por intermédio do tratamento cirúrgico, como se subentende pela revisão da literatura.
5. Beija I, Younes M, Moussa A, et al.: Lipoma arborescens affecting multiple joints. Skeletal Radiol 34: 536-8, 2005.

6. Martin S, Hernandez L, Romero J, et al.: Diagnostic imaging of lipoma arborescens. Skeletal Radiol 27: 325-9, 1998.

7. Siva C, Brasington R, Totty W, et al.: Synovial lipomatosis (lipoma arborescens) affecting multiple joints in a patient with congenital short bowel syndrome. J Rheumatol 29: 1088-92, 2002. 